\title{
ARTICLE OPEN Breast cancer cell adhesome and degradome interact to drive metastasis
}

\author{
Asif Rizwan ${ }^{1}$, Menglin Cheng ${ }^{1}$, Zaver M Bhujwalla ${ }^{1,2}$, Balaji Krishnamachary' ${ }^{1}$ Lu Jiang ${ }^{1}$ and Kristine Glunde ${ }^{1,2}$
}

BACKGROUND: Although primary breast tumors are detected early in most cases, it is inevitable that many patients remain at risk for future recurrence and death due to micrometastases. We investigated interactions between the degradome and the adhesome that drive metastasis, and have focused on matrix metalloproteases (MMPs) within the degradome and integrins and E-cadherin within the adhesome.

AIMS: The aim of this study is to identify interaction networks between adhesion molecules and degradative enzymes in breast cancer metastasis.

METHODS: We compared non-metastatic (BT-474, T47D, MCF7) and metastatic (MDA-MB-231, SUM149, SUM159) human breast cancer cell lines and xenografts, in which we measured growth rate, migration, invasion, colony formation, protein expression, and enzyme activity in vitro and in vivo.

RESULTS: The metastatic breast cancer lines and xenografts displayed higher expression and activity levels of MMPs, which was also confirmed by noninvasive imaging in vivo. These metastatic breast cancer models also displayed elevated heterophilic cell-extracellular matrix (ECM) and lower homophilic cell-cell adhesion compared with those of non-metastatic models. This was conferred by an increased expression of the heterophilic cell adhesion molecule integrin $\beta 1$ (ITGB1) and a decreased expression of the homophilic cell adhesion molecule E-cadherin. Inhibition of MMPs in metastatic cells led to a reduced expression of ITGB1, and stimulation of ITGB1 resulted in higher MMP activities in metastatic cancer cells, demonstrating reciprocal dependencies between degradome and adhesome. Re-expression of E-cadherin (CDH1) led to an increased expression of the precursor form of ITGB1. CONCLUSIONS: Our results point toward a concerted interdependence of MMPs, ITGB1, and CDH1 that is critical for breast cancer metastasis.

npj Breast Cancer (2015) 1, 15017; doi:10.1038/npjbcancer.2015.17; published online 28 October 2015

\section{INTRODUCTION}

The occurrence of metastasis is the most life-threatening aspect of breast cancer. In the first 10 years after diagnosis, up to $12 \%$ of Stage I/II breast cancer patients, whose cancers are locally contained within the breast, die. However, $60 \%$ of Stage III patients, whose cancers have invaded nearby lymph nodes, and over $90 \%$ of Stage IV patients, whose cancers have spread to distant organs, die within 10 years after diagnosis. ${ }^{1}$ Cancer metastasis is driven by networks of proteolytic enzymes, collectively referred to as the degradome, and networks of adhesion molecules, collectively referred to as the adhesome. ${ }^{2}$ Matrix metalloproteases (MMPs) are key players of the tumor degradome. ${ }^{3}$ MMPs act as molecular scissors for cancer cells to chop and dice components of the extracellular matrix (ECM), such as collagen 1 (COL1) fibers, leading eventually to a remodeled ECM that provides an escape path for cancer cells to metastasize. ${ }^{3}$ More than 23 MMPs have been identified in humans, including 6 membrane-type MMPs. ${ }^{4}$

Cancer cell to ECM and cell-to-cell adhesion is, to a large extent, conferred by integrins and E-cadherin. ${ }^{2}$ Integrin $\beta 1$ facilitates cellECM adhesion and movement of tumor cells into the stroma and thus assists in local invasion within the primary site and growth in metastatic sites. ${ }^{5}$ At least 24 different integrin complexes are capable of binding to distinct ECM ligands. ${ }^{6}$ Integrin can also form signaling complexes with oncogenic Her2, Met, and EGF receptors, and it can recruit MMPs to the cell surface for local degradation of ECM in human breast cancer. ${ }^{7}$ E-cadherin promotes homotypic tumor cell-cell adhesion and provides intercellular contacts that confine tumor cells to the primary tumor site. ${ }^{8} \mathrm{MMPs}$, integrins, and E-cadherin are all implicated in breast cancer metastasis. ${ }^{8,9}$

Although previous studies have shown that integrin activation controls metastasis in human breast cancer ${ }^{10}$ and that the cancer degradome contributes to tumor progression, invasion, cell-ECM communication, and the metabolome, ${ }^{11,12}$ the interaction between these two groups of molecular players and its role in metastasis is just emerging. ${ }^{13}$ Our hypothesis that cell adhesion molecules interact with the degradome is supported by (i) co-localized expression of adhesion molecules such as integrins and E-cadherin and degradative enzymes such as MMPs, ${ }^{14}$ (ii) regulation of MMP activities by integrins and E-cadherin, ${ }^{15}$ (iii) regulation of the integrin-mediated adhesome by MMPs, ${ }^{16}$ (iv) binding of key integrins as well as MMPs to the same extracellular matrix (ECM) components, ${ }^{17}$ and (v) interaction between integrins, E-cadherin, and membrane-bound MMPs in cell communication in several types of cancer. ${ }^{16,18}$ Recent findings also revealed that several types of cancer cells have associations between adhesion and degradome molecules. ${ }^{16}$ For example, in melanoma cells, integrin $a_{v} \beta_{3}$ protein binds directly with MMP-2

\footnotetext{
${ }^{1}$ The Johns Hopkins University In Vivo Cellular and Molecular Imaging Center, Division of Cancer Imaging Research, The Russell H. Morgan Department of Radiology and Radiological Science, The Johns Hopkins University School of Medicine, Baltimore, MD, USA and ${ }^{2}$ The Johns Hopkins University School of Medicine, The Sidney Kimmel Comprehensive Cancer Center, Baltimore, MD, USA.

Correspondence: K Glunde (kglunde@mri.jhu.edu)
}

Received 26 June 2015; revised 2 September 2015; accepted 17 September 2015 
and thereby localizes MMP-2 to cell surfaces, and hence assists in ECM, specifically collagen, degradation. ${ }^{13}$ In human melanoma cells, MMP-2 cleaves fibronectin into small fragments to enhance cell adhesion mediated by $a_{v} \beta_{3}$ integrin. ${ }^{16}$ The co-localization of MMP-14 (MT1-MMP) and integrin $\beta 1$ is necessary for local invasion by human adenocarcinoma, epidermoid carcinoma, and fibrosarcoma cells. ${ }^{14}$ It was also shown that MMP-14 and integrin form protein complexes that regulate fibronectin remodeling in murine myoblast cells. ${ }^{19}$ In human osteosarcoma cell lines, integrin $a_{2} \beta_{1}$ positively regulates the expression of MMP-1 and collagen-1a1.20

Over the past 40 years, several generations of MMP inhibitors have been investigated to potentially treat cancer development and metastasis. The first-generation of MMP inhibitors such as marimastat, ilomastat (GM6001) and batimastat were hydroxamatebased inhibitors based on the structure of collagen. ${ }^{21}$ They inhibit several MMPs, such as MMP-1, MMP-2, MMP-7 and MMP-9, by directly binding to $\mathrm{Zn}^{2+}$ ions in the active site. ${ }^{16}$ Clinical studies with these hydroxamate-based broad-spectrum MMP inhibitors were ineffective at doses associated with musculoskeletal toxicity in a phase III trial for metastatic breast cancers that were stable after chemotherapy. ${ }^{22}$ The second generation of hydroxamatebased MMP inhibitors was more selective for specific groups of MMPs, such as for example MMl-166, which is a selective inhibitor of MMP-2, MMP-9, and MMP-14. ${ }^{23}$ However, they still suffered from the general limitation of hydroxamate-based MMP inhibitors that drug metabolism leads to the loss of the hydroxamate $\mathrm{Zn}^{2}$ ${ }^{+}$-binding group and thus were ineffective in human trials. ${ }^{22}$ The second generation of non-hydroxamate MMP inhibitors such as rebimastat, tanomastat, and SB-3CT were developed to avoid metabolic inactivation. ${ }^{24}$ However, their efficacies were inconsistent and opposing outcomes were obtained depending on the timing of administration. The third generation of MMP inhibitors, which are specific to only one target and possess no zinc-binding group, is currently being evaluated preclinically. ${ }^{25}$ MMPs are also involved in cytokine and chemokine activation and inactivation, cell-surface-receptor cleavage and release. ${ }^{26}$ The full potential of MMP inhibitors can only be explored once all MMP functions and all MMP interactions with other important molecules in cancer such as growth factors, apoptotic mediators, and adhesion molecules are fully understood.

In this paper, we have performed comparative studies with a set of non-metastatic (BT-474, T-47D, MCF-7) versus metastatic (MDAMB-231, SUM149, SUM159) human breast cancer cell lines and xenografts. Experiments were performed to determine growth rate, migration and invasion, colony formation, adhesion, aggregation, protein expression (western blot) and activity (zymography). Enzymatically activatable optical imaging probes were utilized to study in vivo tumor degradome activity and angiogenesis. The results provided novel insights into the molecular networks that comprise the cancer adhesome and degradome in breast cancers, and tested how their combined expression and activation drives cancer growth, invasion, ECM remodeling, and metastasis. Our results also suggest that, collectively, the adhesome and degradome molecules expressed in a given tumor can predict the metastatic risk of this primary tumor.

\section{MATERIALS AND METHODS}

\section{Cell culture}

Human breast cancer cell lines, MDA-MB-231, SUM149, SUM159, BT-474, T-47D, and MCF-7, were obtained from the American Type Culture Collection (ATCC, MD, USA). Cells were stably transfected with a construct containing CDNA of tdTomato as outlined in the Supplementary Materials and Methods under 'Cell lines'. ${ }^{27}$ Human mammary fibroblasts were a kind gift from Dr Gary Luker at the University of Michigan. All cells were incubated at $37^{\circ} \mathrm{C}$ with $5 \% \mathrm{CO}_{2}$ in a humidified incubator.
Descriptions of cell-specific culture media are given in Supplementary Materials and Methods under 'Cell type specific media used for breast cancer cell lines'. tdTomato protein expression was detected by fluorescence microscopy using a $\times 20$ objective attached to a Nikon inverted microscope, equipped with a filter set for 528 to $553 \mathrm{~nm}$ excitation and 600 to $660 \mathrm{~nm}$ emission and a Nikon COOLPIX digital camera (Nikon Instruments, Inc, Melville, NY, USA). ${ }^{27}$

MMP expression and relapse-free survival in breast cancer patient The relationship of MMP gene expression and relapse-free survival was evaluated in an integrated multi-study breast cancer transcriptomic data set using Kmplotter (http://kmplot.com). ${ }^{28}$ Kaplan-Meier estimates of 10-year relapse-free survivals (RFS) were calculated with data collected from patients with systemic treatment. The median of gene expression was used to dichotomize data into high- and low-expression groups. Differences in survival curves were evaluated by log-rank test. Significantly different Kaplan-Meier estimators indicate longer RFS for patients with low expression of MMPs compared to the high-expressing group.

Gene analysis of adhesome and degradome in breast cancer cell lines

A breast cancer microarray data set (GSE-16975) was analyzed where the breast cancer cell lines were grown to optimal cell densities for RNA extraction and hybridization on Affymetrix microarrays. ${ }^{29}$ The heat map was generated using the Gene-e matrix visualization and analysis platform (http://www.broadinstitute.org). The heat map represents changes in relative content of adhesome and degradome gene expression levels in 17 metastatic breast cancer cell lines (MDA-MB-231, SUM149, SUM159, MDA-MB-468, MDA-MB-436, MDA-MB-157, MDA-MB-175VII, MDA-MB-361, MDA-MB-435s, BT20, BT549, DU4475, HCC1937, Hs578T, SK-BR-7, SUM102, SUM1315MO2) and 11 non-metastatic breast cancer cell lines (BT-474, T-47D, MCF-7， BT-483， MDA-MB-415，MPE-600，SUM52PE， SUM44PE， ZR-75-1, MDA-MB-134VI, CAMA-1).

\section{Protein-protein interaction network}

Network analysis of potential protein interactions among adhesome and degradome proteins, whose expressions were different in metastatic versus non-metastatic cell lines in the Gene-e analysis, was carried out using the STRING-9.1 (http://string-db.org) computational tool and database with a high confidence interval of $0.7 .^{30}$ The STRING network, composed of the proteins of interest, is constructed based on genomic context, highthroughput experiments, co-expression, and scientific reports. ${ }^{30}$ The network nodes are proteins and edges represent the predicted functional associations. A red line indicates the presence of fusion evidence; a green line neighborhood evidence; a blue line co-ocurrence evidence; a purple line experimental evidence; a yellow line text-mining evidence; a light blue line database evidence; a black line co-expression evidence. ${ }^{30}$ Clustering algorithms $\left(K_{\text {means }}=2\right)$ were used to extract relevant modules. ${ }^{30}$ Intercluster edges are represented by dashed-lines. ${ }^{30}$

\section{In vitro assays}

We performed a number of assays to characterize the tdTomato-expressing breast cancer cell lines used in our studies. Cell proliferation was assessed with the WST-1 assay. A series of protease activity and adhesion assays were performed such as zymography to assess MMP activities, cell adhesion assays, hanging drop assays, cell aggregation assays, clonogenic assays, quantitative reverse transcription PCR (qRT-PCR), immunoblotting protein assays, cell migration, and invasion assays. E-cadherin transfection was done using E-cadherin-GFP, which was a kind gift from Jennifer Stow (Addgene plasmid \# 28009). Experimental details are provided in Supplementary Materials and Methods under 'In vitro assays'.

\section{In vivo and ex vivo fluorescence imaging}

Optical imaging was carried out using the Xenogen IVIS 200 Spectrum system. Enzymatically activatable optical imaging probes MMPSense-680 (NEV10126), and AngioSense-750 (NEV10011EX) from PerkinElmer (Waltham, MA, USA) were injected into the tail veins of mice growing orthotopic tumor xenografts according to the manufacturer's protocol. MMPSense is activated by MMP-2, $-7,-9,-12,-13$, and -14 . AngioSense injection enables imaging of tumor blood vessels and was used for normalization of uneven delivery of the probes to the tumor. Each mouse 
was imaged at $24 \mathrm{~h}$ after the injection with the IVIS camera settings at 1 and $2 \mathrm{~s}$ exposure time, binning factor of 8 , field of view of $18.8 \mathrm{~cm}$, and $\mathrm{f}$ number of 2 . Then, the animals were killed and tumor xenografts and lungs were excised for ex vivo fluorescence imaging. Four to six 2-mm thick fresh tissue sections were cut from the primary tumor using an adjustable tissue slicer (Braintree Scientific, Braintree, MA, USA). Tumor sections and whole lungs were imaged with IVIS camera settings at 1- and 2-s exposure time, binning factor of 8 , field of view of $6.4 \mathrm{~cm}$, and $f$ number of 2 . All experiments were carried out according to the approved guidelines of the Institutional Animal Care and Use Committees (IACUCs) of the Johns Hopkins University.

Ex vivo preparation of tumor sections and histopathology

Following ex vivo imaging, tissues were fixed in $4 \%$ paraformaldehyde for $24 \mathrm{~h}$ and embedded in paraffin blocks. Serial sections of 5- $\mu \mathrm{m}$ thickness were cut from the formalin fixed, paraffin embedded tissue blocks and floated onto charged glass slides (Super-Frost Plus, Fisher Scientific, Pittsburgh, PA, USA). ${ }^{31,32} \mathrm{~A}$ hemotoxylin and eosin stained section was obtained from each tissue block. Unstained sectioned were further processed for immunohistochemical detection of MMP-1, MMP-9, and ITGB-1 as detailed in Supplementary Materials and Methods under 'Immunohistochemistry'.

\section{Quantification and statistical analysis}

Statistically significant differences between quantitative measurements were analyzed by unpaired Student's $t$-test. $P<0.05$ was considered statistically significant. Box-and-Whisker plots for cell migration, invasion, and adhesion were generated by BoxPlotR (Montréal, Québec, Canada), where the center lines show the medians, box limits indicate the 25th and 75th percentiles as determined by $\mathrm{R}$ software (Vienna, Austria), whiskers extend 1.5 times the interquartile range from the 25th to 75 th percentiles, and outliers are represented by dots. ${ }^{33} \mathrm{~A}$ one-way analysis of variance was calculated from the number of migrated or invaded cells in all experimental groups. Post hoc comparisons using the Fisher least significant difference were explored to compare the mean of one group with the mean of another group. $P<0.05$ was considered statistically significant. In vivo MMP activity was measured for each pixel by calculating the ratio of MMPsense divided by Angiosense optical signal intensity using in-house software written in Matlab (Natick, MA, USA). Box plots for MMP activity were also generated using Matlab.

\section{RESULTS}

Adhesome and degradome molecules in metastatic versus nonmetastatic breast cancers

In an analysis of 1,144 genes from a panel of 28 human breast cancer cell lines given in the GEO data set GSE16795, ${ }^{29}$ we have demonstrated that metastatic compared with non-metastatic breast cancer cells contain significantly $(P<0.01)$ increased messenger RNA (mRNA) gene expression levels of integrin $a-1$, $a-4, a-5, a-6, a-V$, and $\beta-1$, a decreased level of E-cadherin, and increased levels of MMP-2, $-3,-11,-14,-16$, and -19 as shown in Figure 1a. Some genes display significant changes in more than one microarray probe. To compare metastatic nodules with the corresponding primary breast cancers, we have analyzed the GEO data set GSE2603, where the lung-metastatic nodules of tail-veininjected MDA-MB-231 breast tumor xenografts were expanded in cell culture. The lung-metastatic (LM) cell lines showed an increased gene expression of integrin $a-1, a-4, a-5, a-6, a-V$, and $\beta-1$, E-cadherin, and MMP-1, $-2,-3,-11,-16$, and -24 compared with wild-type MDA-MB-231 breast cancer cells (WT) as shown in Figure $1 \mathrm{~b} .{ }^{34}$ It should be noted here that tail vein injected breast cancer cells represent a subpopulation of cancer cells with increased tendency to colonize a particular organ. ${ }^{35}$

\section{Analysis of interacting proteins within the degradome and} adhesome

To identify known and potential protein-protein interactions relevant to the adhesome and degradome, we used the STRING 9.1 software and database. STRING quantitatively integrates protein interaction data from multiple sources for a large number of organisms. Using STRING, we identified several members of the MMP family (MMP-1, -2, -3, -7, -9, -11, -13,-14, -16, -19), integrin family (ITGA-1, $-3,-4-,-5,-6,-\mathrm{V}$, ITGB-1, -3 ) and the E-Cadherin molecule that have direct and indirect associations with each other, as well as associations with major ECM components such as collagen, laminin, and fibronectin (Figure 1C). E-cadherin directly interacts with MMP-1, MMP-2, MMP-3, MMP-7, MMP-9, MMP-14, and MMP-19. ITGB-1 directly and indirectly interacts with MMP-2, -9 , and -14. Overall, E-cadherin and the MMPs have a larger number of interactions and thus form a cluster. The integrins form a cluster with the major ECM molecules such as collagen, fibronectin, and laminin.

Clinical relationship between the degradome and metastasis in breast cancer

Breast tumors with an overexpression of MMPs are associated with invasion and metastases. ${ }^{9}$ In our analysis of clinical data sets taken from the KM-Plotter database, ${ }^{36}$ we show that significantly increased expression levels of MMP-2 $(P=1.5 \mathrm{e}-6)$, MMP-9 $(P=0.027)$, and MMP-14 $(P=0.00051)$ were predictive of a decreased RFS in chemotherapy treated ER- human breast cancer patients $(n=211)$. High expression levels of MMP-1 $(P=0.00012)$ and MMP-9 $(P=0.00022)$ were predictive of a decreased RFS in endocrine treated ER+ human breast cancer patients $(n=690)$ as shown in Figure 1d. Overall, our data analysis supports the roles of MMPs in breast cancer aggressiveness. High expression of MMP-2 $(P=1.5 \mathrm{e}-6)$, MMP-9 $(P=0.027)$, and MMP-14 $(P=0.00051)$ is predictive of lower RFS in chemotherapy treated for ER - human breast cancer patients. High expression of MMP-1 $(P=0.00012)$, and MMP-9 $(P=0.00022)$ is predictive of lower RFS in endocrine treated ER+ human breast cancer patients. These Kaplan-Meier curves were generated using KM plotter from http://kmplot.com.

Characterization of constitutively tdTomato-expressing metastatic and non-metastatic breast cancer models

We have performed comparative in vitro and in vivo/ex vivo experiments with human breast cancer cell lines and xenografts as outlined in Supplementary Figure 1A. All cell lines such as MDAMB-231, SUM149, SUM159, BT-474, T-47D, MCF-7 were engineered to constitutively express tdTomato fluorescent protein for assessing tumor growth and metastatic spread by optical imaging in vivo and ex vivo (Supplementary Figures 1B-D). Proliferation assays of the tdTomato-expressing breast cancer cell lines demonstrated that all three metastatic lines grew significantly faster than the non-metastatic lines (Supplementary Figure 1E). Clonogenic assays of the tdTomato-expressing breast cancer cell lines were performed to examine whether a single cell can grow into a colony in uncoated, collagen 1 coated, and matrigel-coated plates within 2 weeks (Supplementary Figures $2 \mathrm{~A}$ and $\mathrm{B}^{37}$ ). Metastatic tdTomato-expressing MDA-MB-231 and SUM159 cells grew a significantly $(P<0.01)$ higher number of colonies compared with all three tdTomato-expressing non-metastatic cell lines on uncoated, collagen 1 coated, and matrigel-coated plates. Metastatic tdTomato-expressing SUM149 cells formed fa significantly $(P<0.01)$ increased number of colonies on uncoated surfaces, but not in collagen1, and matrigel-coated surfaces, compared with all three non-metastatic cell lines.

We also tested the migration and invasion capabilities of all tdTomato-expressing cell lines. In transwell migration and invasion assays, significantly fewer non-metastatic tdTomato-expressing cell lines (BT-474, T-47D, MCF-7) migrated or invaded through the $8 \mu \mathrm{m}$ pores of a transwell chamber compared with metastatic tdTomato-expressing cell lines (MDA-MB-231, SUM149, SUM159; Figures $2 \mathrm{a}$ and $\mathrm{b}$ ). In these migration and invasion assays, around $90 \%$ of tdTomato-expressing SUM149 and SUM159 cells were detected on the bottom surface of the insert and the remaining 
$10 \%$ were attached to the plate well. For tdTomato-expressing MDA-MB-231 cells, around $20 \%$ of the cells migrated or invaded to the bottom surface of the insert, while the remaining $80 \%$ were attached to the well. All three metastatic cell lines showed higher migration and invasion compared with the migration and invasion by the non-metastatic cell lines (Supplementary Table 1). It should

a

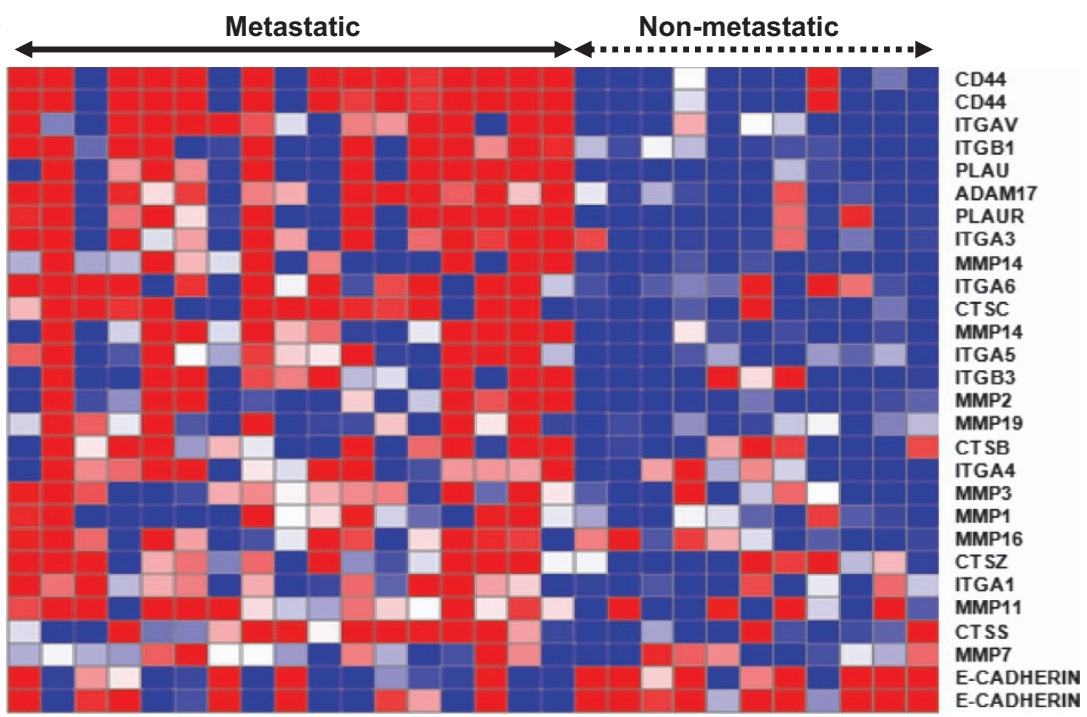

b

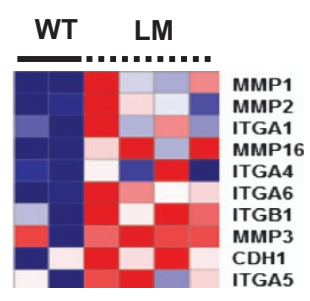

d
C

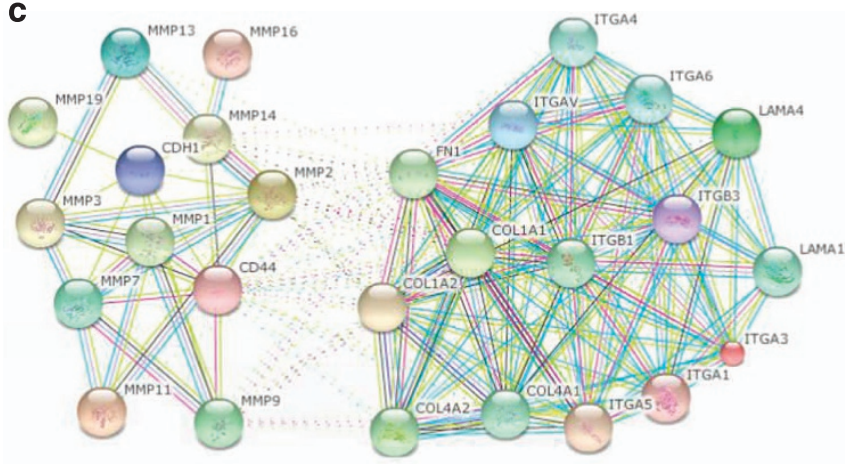

ER-patients, Chemotherapy treated
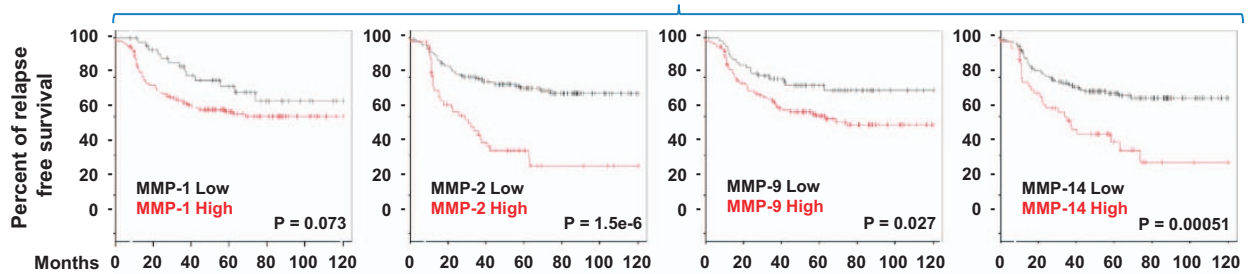

ER+ patients, Endocrine treated

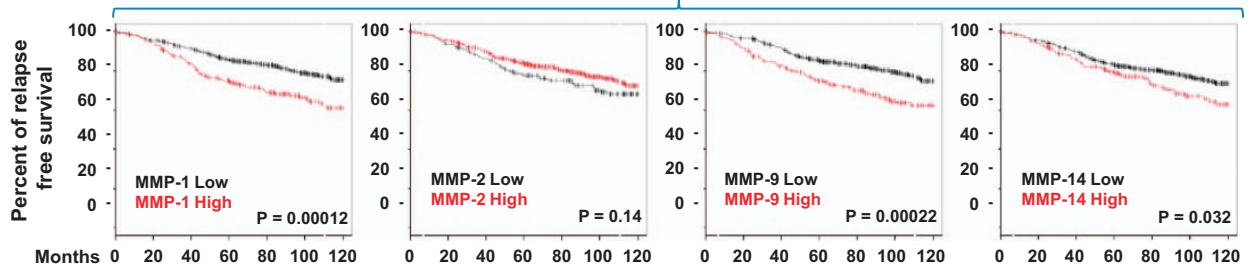

Figure 1. Analysis of publicly available microarray messenger RNA (mRNA) expression data from clinical breast tumors and breast cancer cell lines. (a) Expression levels of key adhesion molecules and key degradative enzymes discriminate between metastatic $(n=17)$ and non-metastastic $(n=11)$ human breast cancer cell lines (GSE16795). (b) MMPs, integrins and E-cadherin that are increased in subpopulations of lung-metastatic MDA-MB-231 (LM) compared with parental MDA-MB-231 (WT) cells (GSE2603). (c) Protein interaction network of major cell adhesion and degradome molecules differentially expressed in metastatic versus non-metastatic cell lines. (d) Kaplan-Meier curves show that high expression levels of MMP-2, MMP-9, and MMP-14 are predictive of decreased relapse-free survival in chemotherapy treated ER - human breast cancer patients, while high expression levels of MMP-1 and MMP-9 are predictive of decreased relapse-free survival in endocrine treated ER+ human breast cancer patients. 
a
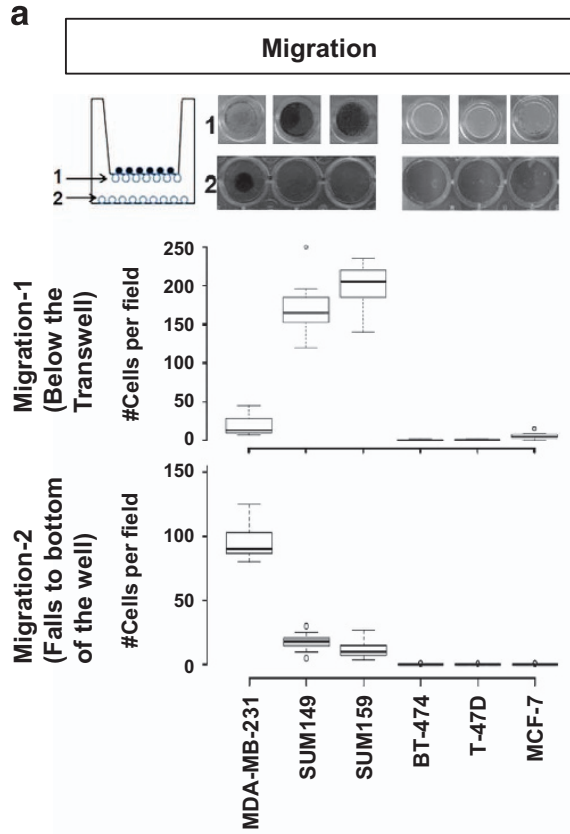

b
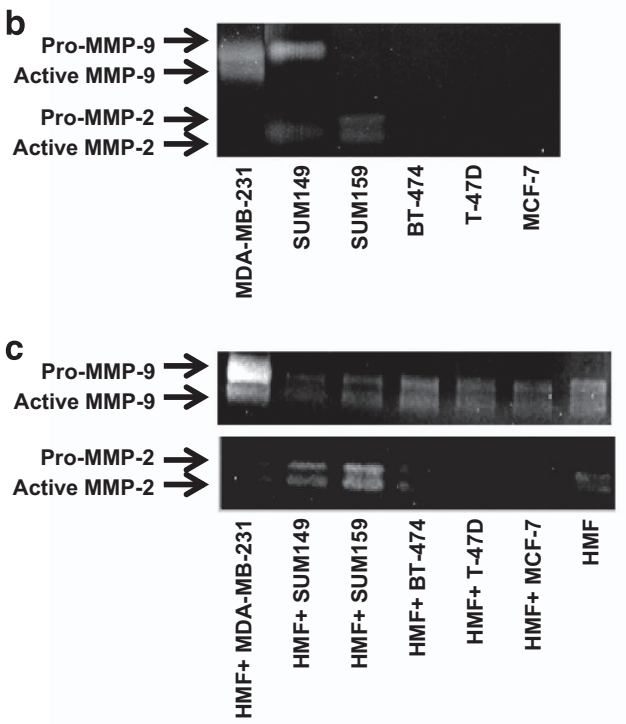
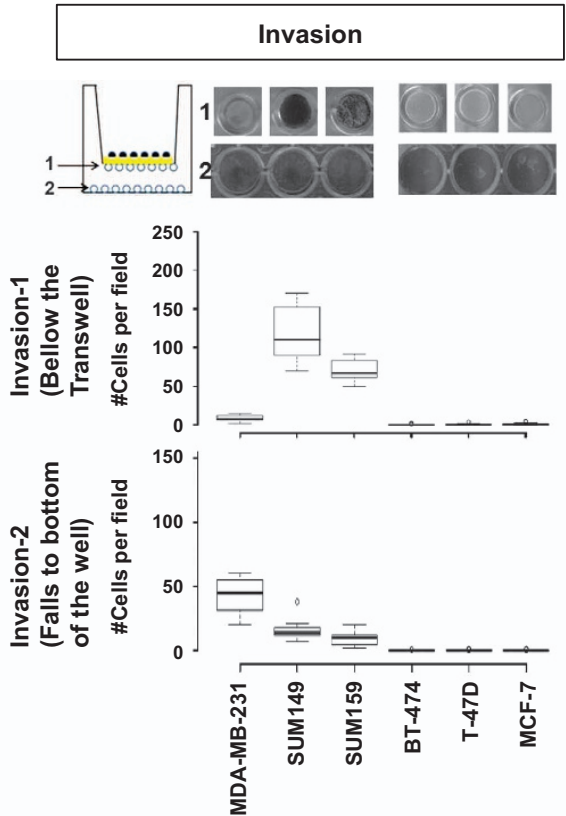

d
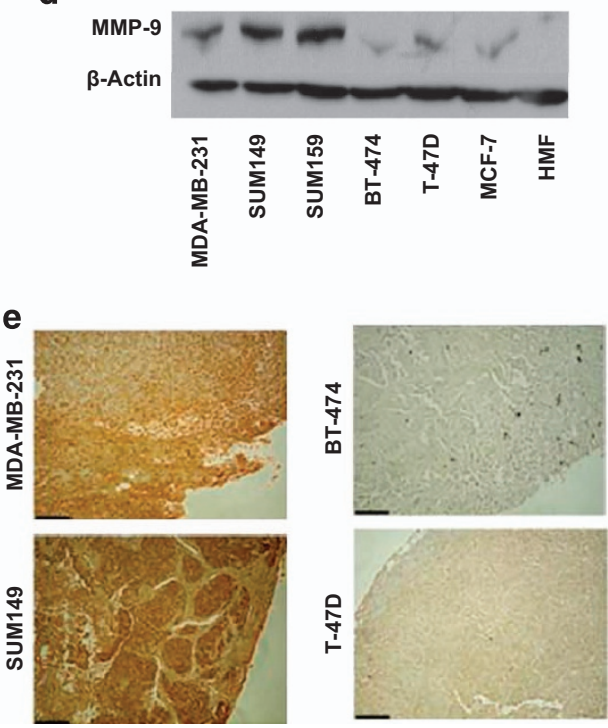

Figure 2. Invasion and MMP expression and activity in human breast cancer cell lines. (a) Breast cancer cell lines were allowed to migrate or invade matrigel for $48 \mathrm{~h}$, and were stained with crystal violet. Representative photographs of the membrane insert and well from the transwell migration and invasion assays are shown. Average numbers of migrating and invading cells per field of view were plotted as Box-and-Whisker plots. Statistical testing for significant differences is shown in Supplementary Table 1. (b) In vitro MMP-2 and MMP-9 activity were measured using gelatin zymography. Conditioned media were collected after $24 \mathrm{~h}$ of incubation. Photographs show pro-MMP-2 (72 kDa), active MMP-2 (62 kDa), pro-MMP-9 (90-100 kDa), and active MMP-9 (82 kDa). (c) MMP-2 and MMP-9 activity measured by gelatin zymography of breast cancer cells that were co-cultured with HMF for $24 \mathrm{~h}$. (d) Western blots showing MMP-9 expression in breast cancer cell lines. High MMP-9 expression was observed in metastatic lines, whereas non-metastatic lines and fibroblasts expressed small amounts or no MMP-9. B-actin was used as loading control. (e) Immunohistochemistry analysis showing MMP-9 expression in sections from metastatic breast tumor xenografts. Scale bars, $100 \mu \mathrm{m}$.

be noted here that the migration and invasion properties of tdTomato-expressing cells and wild-type cells were comparable for all of the six cell lines that we have used in our experiments (data not shown).

MMP expression and activity profiles in metastatic versus non-metastatic breast cancer cell lines and xenografts Breakdown of basement membrane is a critical step for tumor invasion. Loss of basement membrane type IV collagen is associated with increased activities of MMP-2 and MMP-9. ${ }^{38}$ To investigate the possible involvement of these proteases in our cell lines, gelatin zymography analyses from serum-free conditioned media were performed. As shown in Figure 2b, active MMP-9 was detected in medium conditioned by MDA-MB-231 cell and MMP-2 was detected in medium conditioned by SUM149 and SUM159 cells. Cancer-associated fibroblasts are also known to contribute to MMP activity in vivo. ${ }^{39}$ We have examined the conditioned media of cancer cells co-cultured at a 1:1 ratio with human mammary fibroblasts (HMF) with gelatin zymography. HMF alone are able to 


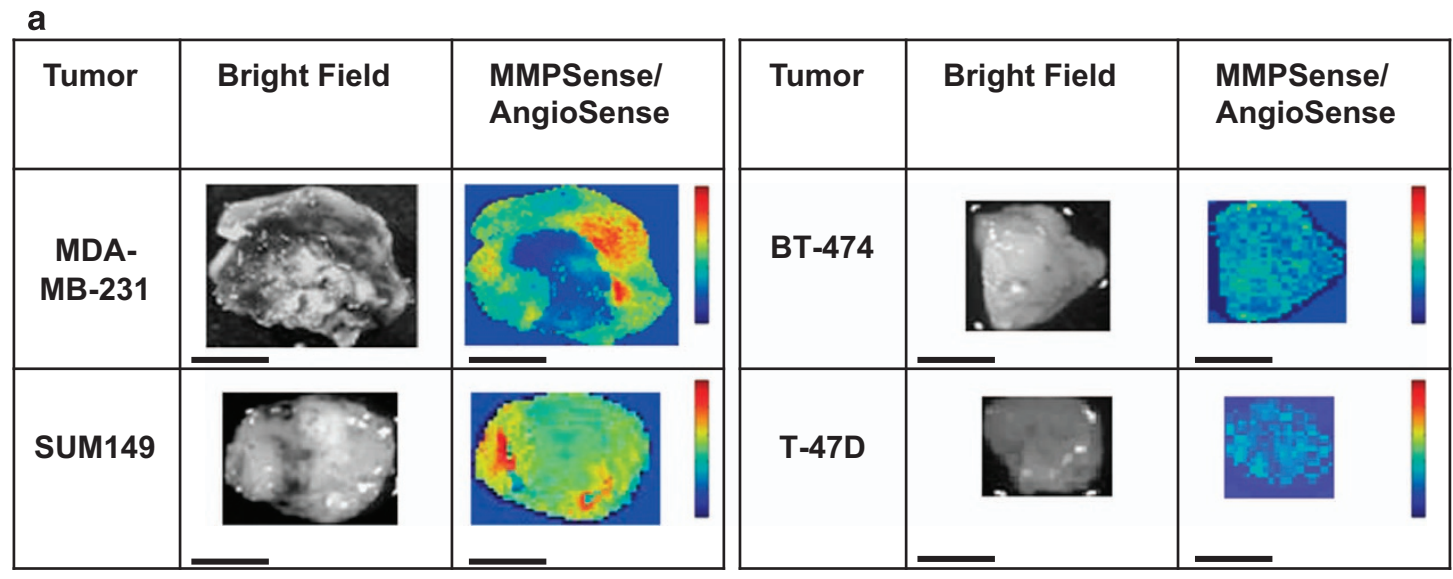

b

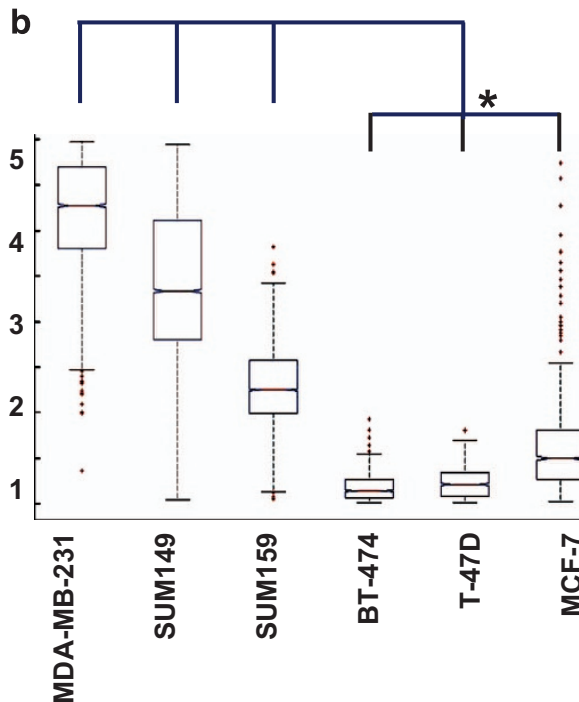

C

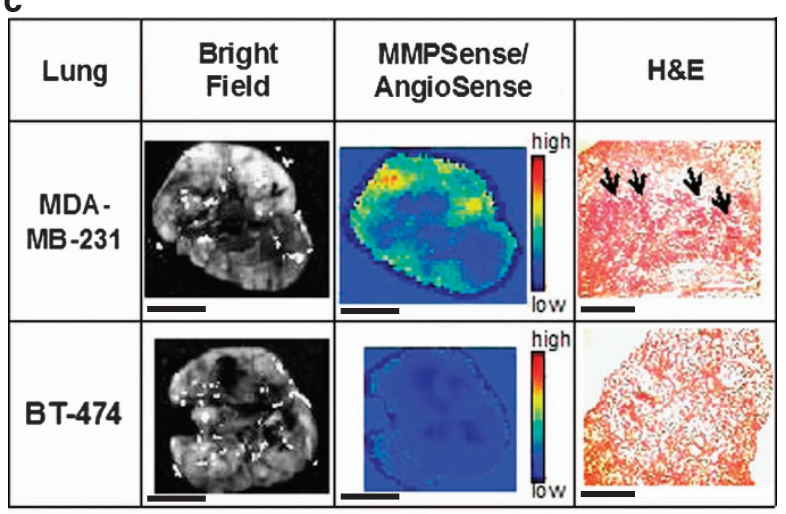

Figure 3. Analysis of MMP activities in breast cancer xenograft models. (a) Ex vivo fluorescence images of MMP activity in fresh breast tumor xenograft slices measured following MMPSense and AngioSense injection. Scale bar, $5 \mathrm{~mm}$. (b) Box plots show the intensity of MMP fluorescent signals normalized to AngioSense to normalize for uneven delivery of the probe. ${ }^{*} P<0.05$. (c) Lungs of mice growing metastatic breast cancer xenografts displayed increased MMP activity. Scale bar, $5 \mathrm{~mm}$. Corresponding H\&E stains showed micrometastases in these lungs as pointed out by arrows. Scale bar, $2.5 \mathrm{~mm}$.

produce pro-forms and active forms of MMP-2 and MMP-9. The activity of active MMP-2 was enhanced when HMF were co-cultured with MDA-MB-231, and active MMP-9 activity was enhanced when HMF were co-cultured with SUM149 or SUM159 cancer cells (Figure 2c). Western blot analysis of cell lysates revealed higher expression levels of MMP-9 in the metastatic cell lines, but no expression in the non-metastatic cell lines (Figure $2 \mathrm{~d}$ ). Immunohistochemical staining of tumor xenograft sections showed higher MMP-9 expression levels in the metastatic versus non-metastatic xenograft models (Figure 2e). Collagenase-type MMP-13 and membrane-type MMP-14 expression did not show any significant change across the tested panel of cell lines. However, collagenase MMP-1 and MMP-8 were significantly increased in metastatic cell lines as seen by immunohistochemistry $(\mathrm{IHC})$ and western blot, respectively (Supplementary Figures $3 \mathrm{~A}$ and $\mathrm{B})$.

Using MMP-activatable fluorescent imaging agents that are activated by key MMPs, we observed that metastatic breast tumors displayed increased MMP activities compared with nonmetastatic breast tumors, which was shown in fresh 2-mm thick tumor sections ex vivo in Figure 3a. The resulting quantitative MMP activities, normalized to perfusion to account for agent delivery to the tumor, are shown in a box plot in Figure 3b. The lungs of mice growing primary tumor xenografts were also imaged for MMP activity. MMP activity in the lungs of mice with metastatic primary tumors was evident prior to metastatic seeding in the lungs, indicating that the secretion of degradative enzymes by the metastatic tumor or stroma occurs well in advance of metastatic seeding in distant organs, which is in good agreement with previous studies. ${ }^{40}$

Strong heterophilic and weak hemophilic adhesion signature in primary metastatic breast cancer cell lines and tumor xenografts Metastatic cells displayed increased adhesion compared to nonmetastatic cells on ECM surfaces as measured by cell adhesion assay shown in Figure 4a. The immunoblots of cells, as well as immunohistochemistry (IHC) of tumor xenografts, consistently demonstrated an increased expression of the heterophilic adhesion molecule integrin $\beta 1$ (ITGB1) in metastatic tumors compared to non-metastatic tumors (Figures $4 \mathrm{~b}$ and $\mathrm{c}$ ). Metastatic cell lines showed decreased cell aggregation in the hanging drop assay and in collagen 1 gel (Figure 5a). When co-cultured with HMF, metastatic cells displayed increased adhesion to fibroblasts in the hanging drop assay (Figure 5b). Compared with nonmetastatic cells, metastatic cells had a significantly decreased 
a

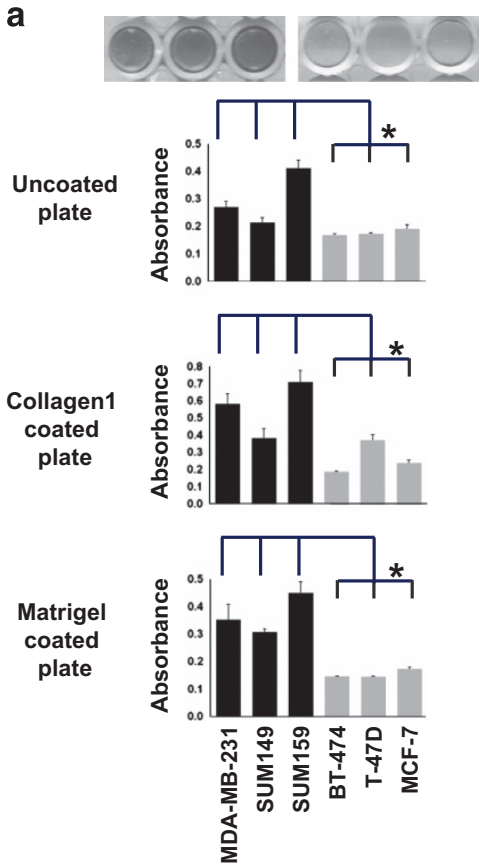

b

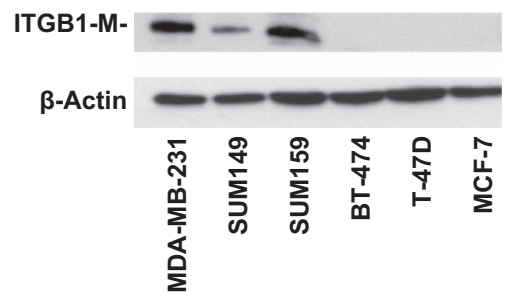

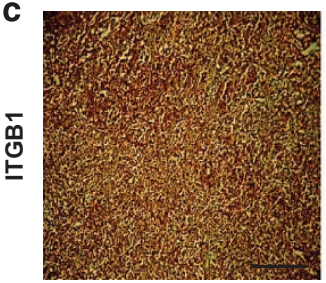

MDA-MB-231

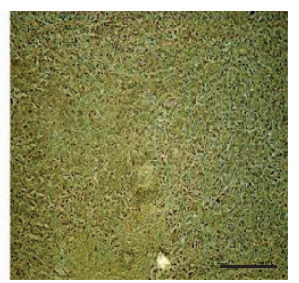

BT-474

Figure 4. Analysis of cell adhesion and integrin $\beta 1$ expression in breast cancer cell lines and xenograft models. (a) Representative photographs of cell adhesion assays where plates were coated with collagen $1(50 \mu \mathrm{g} / \mathrm{ml})$. The column graphs represent quantitative cell adhesion assays on uncoated, collagen 1 coated, and matrigel-coated plates. Light absorbance from the WST-1 assay, which is proportional to the number of cells adhering to the plate, is displayed on the $y$-axis. Values are mean \pm s.d. ${ }^{*} P<0.05$. (b) Immunoblots showed significant differences in mature integrin $\beta 1$ expression in highly expressing metastatic cells compared with non-expressing non-metastatic cells. (c) Immunohistochemistry analysis demonstrated strong integrin $\beta 1$ expression in metastatic MDA-MB-231 tumor sections, but not in non-metastatic BT-474 tumor sections. Scale bar, $200 \mu \mathrm{m}$.

expression level of the homophilic adhesion molecule E-cadherin $(\mathrm{CDH} 1)$ both in vitro and in vivo (Figures $5 \mathrm{c}-\mathrm{e})$.

Interaction of degradome and adhesome

The major integrin $\beta 1$ binding site is an Arg-Gly-Asp (RGD) peptide, which is present in a variety of ligands, which are part of the ECM such as collagen, laminin, and fibronectin and thereby represents a major recognition system for cell adhesion. ${ }^{41}$ We analyzed the effect of an RGD-containing peptide, namely Arg-Gly-Asp-Ser (RGDS), on the regulation of MMP secretion in cultured cells. When RGDS peptide was added to cell culture medium, the secreted gelatinases MMP-2 and MMP-9 increased in the metastatic MDA-MB-231 and SUM159 cell lines, as shown in Figure 6a. However, cellular integrin $\beta 1$ protein, as analyzed by western blot, did not show any differences in expression level when the cells were treated with various concentrations of RGDS (Figure $6 \mathrm{~b}$ ). On the other hand, the mature form of integrin $\beta 1$ protein significantly decreased $(P<0.01)$ when metastatic MDA-MB-231 and SUM159 cells were treated with the broadspectrum MMP inhibitor marimastat or with the MMP-2 and MMP-9 inhibitor SB-3CT for $48 \mathrm{~h}$ (Figure 6c). This suggests a reciprocal regulatory relationship between MMP-2/MMP-9 and integrin $\beta 1$. It should be noted that the fourth amino-acid $S$ in RGDS contributes toward the stability of the RGDS confirmation to fit the integrin receptors. ${ }^{42}$ Cells that were cultured in medium containing RGD sequence alone did not show any changes in the amount of MMP secretion.

Next, we transfected MDA-MB-231 and SUM159 cells to re-express the E-cadherin gene. ${ }^{43}$ Although we were able to detect E-cadherin gene expression by qRT-PCR in the transfected cells (Supplementary Figure 3), E-cadherin protein was not detected by western blot, most likely due to post-translational $\mathrm{E}$-cadherin degrading mechanisms that are present in metastatic breast cancer cells. ${ }^{44,45}$ Nevertheless, we observed that E-cadherin re-expression at the $m R N A$ level reduced protein expression of the mature form of integrin $\beta 1$ in metastatic MDA-MB-231 and SUM159 cells (Figure 6d, Supplementary Figure 4). A significantly lower number of cells with E-cadherin re-expression were able to migrate or invade in transwell assays (Figure 6e).

\section{DISCUSSION}

Our study presents several important findings: (i) Increased expression and activity of MMP-2 and MMP-9 among others in metastatic breast cancer cell lines, xenografts, and lungs as compared with non-metastatic lines. (ii) Heterophilic adhesion, likely mediated by integrin $\beta 1$, is increased in metastatic compared to non-metastatic lines. (iii) Homophilic adhesion, likely mediated by E-cadherin, is increased in non-metastatic compared to metastatic lines. (iv) Re-expression of E-cadherin reduced the expression of the mature form of integrin $\beta 1$ in metastatic breast cancer cells. (v) A reciprocal interaction exists between integrin $\beta 1$ and MMP-2/MMP-9 in metastatic breast cancer cells.

We observed that MMP-2 and MMP-9 activities, among other MMP activities, are increased in metastatic breast cancer cell lines, xenografts, and lungs as compared with non-metastatic lines. Our analysis of publicly available clinical and cellular expression data revealed that low levels of MMP-1, $-2,-9$, and -14 are important for breast cancer survival. However, a slew of other MMPs also confer breast cancer metastasis, depending on the particular cell lines studied. Since elevated MMPs are an important component of many aggressive tumors, it is a potential drug target for cancer therapy. ${ }^{9}$ Despite promising preclinical data, clinical trials using MMP inhibitors resulted in inconsistent outcomes. As evident from our data and the data of others, ${ }^{40}$ a key issue is that the types and levels of MMP expression and activity are quite variable across different breast tumors and the derived breast cancer cell lines, 

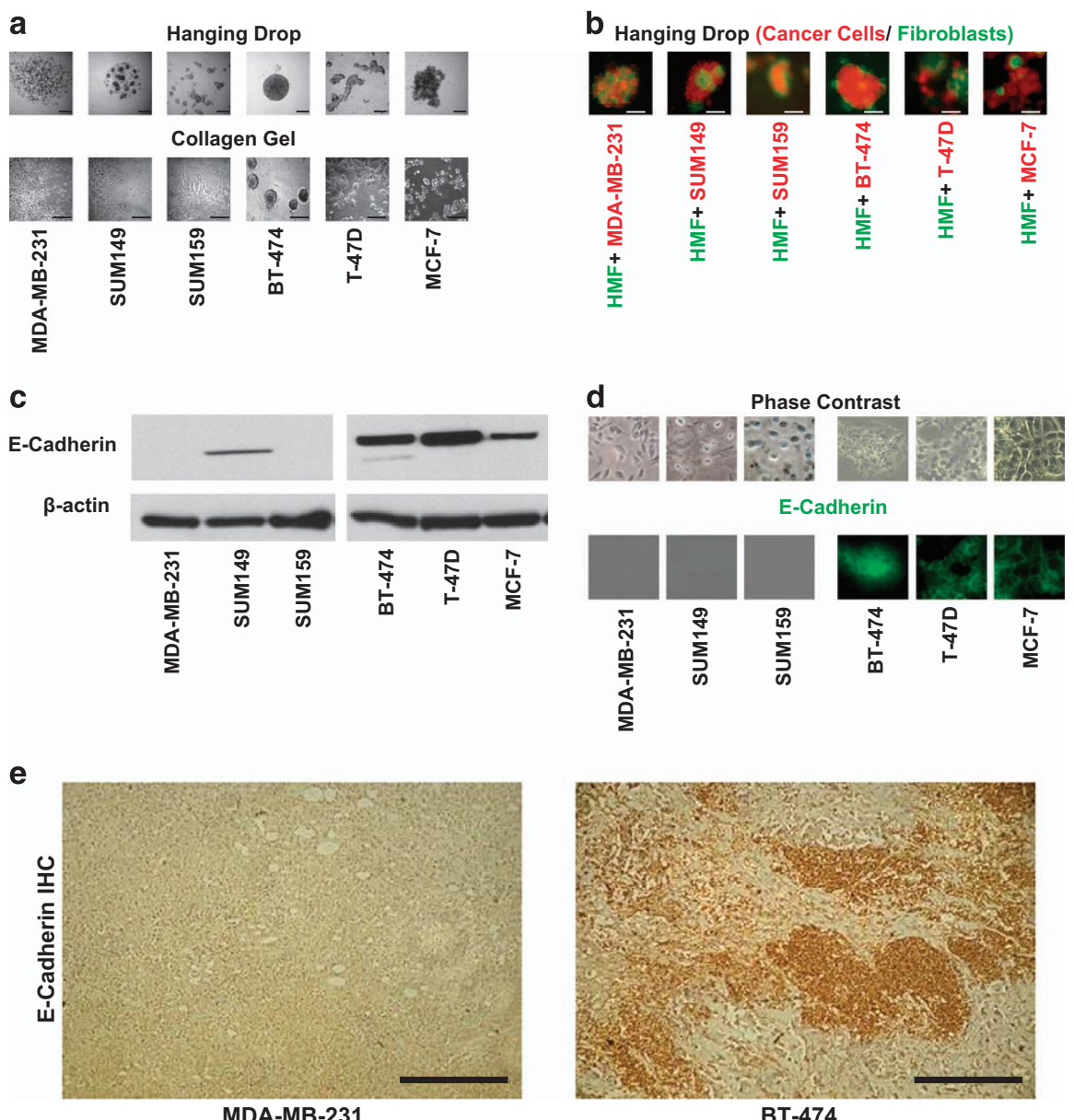

Figure 5. Homophilic and heterophilic cell adhesion characteristics and E-cadherin expression in breast cancers. (a) Metastatic cell lines showed lower cell aggregation in hanging drop assays and collagen 1 gel as compared to non-metastatic cell lines. Scale Bar, $200 \mu \mathrm{m}$. (b) Equal numbers of red-labeled breast cancer cells and green-labeled fibroblasts were mixed and evaluated in the hanging drop assay. Metastatic cells adhered to fibroblasts and formed a mixed population. Non-metastatic cells remained aggregated in a sphere and separated from fibroblast cells. Scale Bar, $200 \mu \mathrm{m}$. (c) Western blots showed significant differences in E-cadherin expression in lowly expressing metastatic cells compared with highly expressing non-metastatic cells. (d) Immunofluorescence staining demonstrated lower expression of E-cadherin in metastatic cells as compared to non-metastatic cells. (e) Immunohistochemistry analysis showing weak E-cadherin expression in metastatic MDA-MB-231 tumor sections, and high E-cadherin expression in non-metastatic BT-474 tumor sections. Scale bar, $200 \mu \mathrm{m}$.

which is one of the main reason for the inconsistent outcomes in clinical trials using MMP inhibitors. However, systemic treatment with MMP inhibitors would be a good way of treating breast cancer metastasis, as MMP activity in metastatic sites is upregulated during or even prior to metastatic seeding, ${ }^{40}$ as also observed in the lungs of our metastatic tumor xenograft model.

We showed that mature active integrin $\beta 1$ expression was elevated in metastatic breast cancer cell lines that adhered to the ECM components collagen 1 and matrigel, while non-metastatic cell lines contained no integrin $\beta 1$ and did not adhere well. We also observed that metastatic breast cancer cell lines displayed increased heterophilic adhesion. It is known that integrin heterodimers containing $\beta 1$ subunits are receptors for various types of ECM molecules such as collagens, laminins, fibronectin, and tenascin, and thus have an essential role in cell-ECM adhesion. ${ }^{46}$ In addition, $\beta 1$ integrins initiate signaling cascades in the cell in response to extracellular chemokines (outside-in), and also transmit intracellular signals that change the way the cells interact with the ECM (inside-out). ${ }^{6}$ These signaling pathways regulate cell adhesiveness by changing the conformation of $\beta 1$ integrin binding to the ECM. ${ }^{5}$ These dynamic adhesion processes are crucial for conferring the migration abilities of cancer cells, which degrade mammary basement membrane, the dense ECM surrounding the tumor, and the ECM of the walls of blood vessels.

In our study, E-cadherin was increased in non-metastatic breast cancer cell lines that adhere well to each other but not to fibroblasts, as compared with metastatic breast cancer cell lines. This finding is in good agreement with the suggestion that dynamic E-cadherin-mediated cell-cell adhesions and integrinmediated cell-ECM adhesions govern the invasive and metastatic potential of tumors. ${ }^{8}$ Loss of E-cadherin results in the weakening of cell-cell adhesion. ${ }^{8}$ On the other hand, increase in integrin- $\beta 1$ subunits mediates cell-ECM interactions by linking signals from the environment to the actin cytoskeleton. ${ }^{6}$ Simultaneously, these two processes enhance the agility of metastatic breast cancer cells, which let them respond to external signals and execute successful migration and invasion. ${ }^{8}$

We observed that E-cadherin gene re-expression in metastatic breast cancer cells reduced the amount of mature integrin $\beta 1$ protein in metastatic breast cancer cells. In the clinical setting, it was shown that the secondary metastatic site can induce the re-expression of E-cadherin in cancer cells, which is a critical step in the survival of cancer cells in the new microenvironment. ${ }^{47}$ The effect of re-expressing E-cadherin on integrin $\beta 1$-subunits has, to 
the best of our knowledge, not been studied so far. Our data suggest that reducing the amount of active integrin $\beta 1$ increases the expression of E-cadherin. Taken together, our data indicate that a reciprocal interaction exists between E-cadherin and integrin $\beta 1$, which couples homophilic cell-cell and heterophilic cell-ECM adhesion in metastatic breast cancer cells. This will enable metastatic breast cancer cells to lose contact to other cells at a time when they start binding to the ECM while they migrate, and switch back to binding to cells instead of ECM when they arrest and colonize distant sites.

We found that RGD-stimulation of metastatic breast cancer cells upregulated the expression of MMP-2 and MMP-9. Vice versa, when we inhibited MMP activities in cell culture by either Marimastat or SB-3CT, the expression of integrin $\beta 1$ was significantly reduced. Our experiments with the MMP inhibitors Marimastat and SB-3CT showed for the first time that
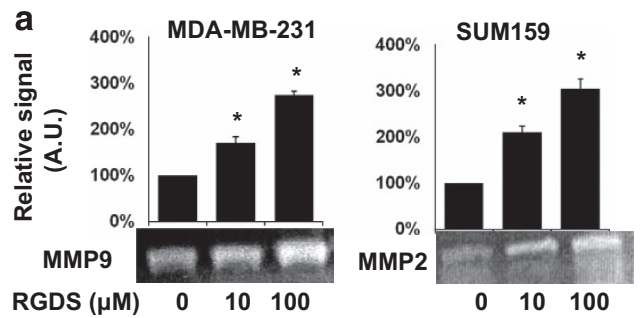

C
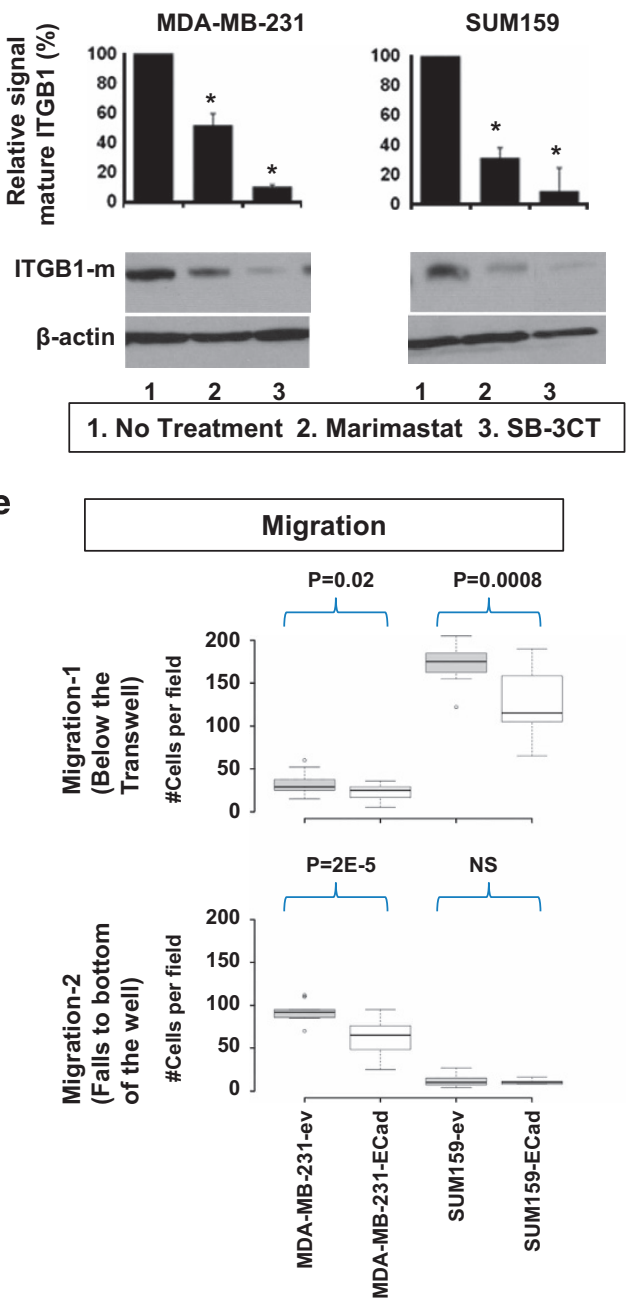

b

MDA-MB-231

SUM159

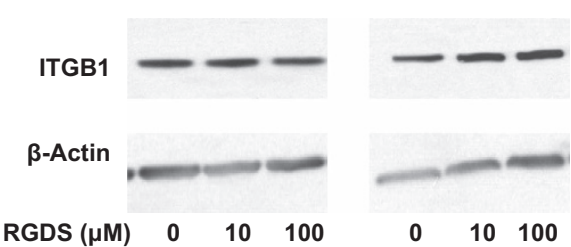

d
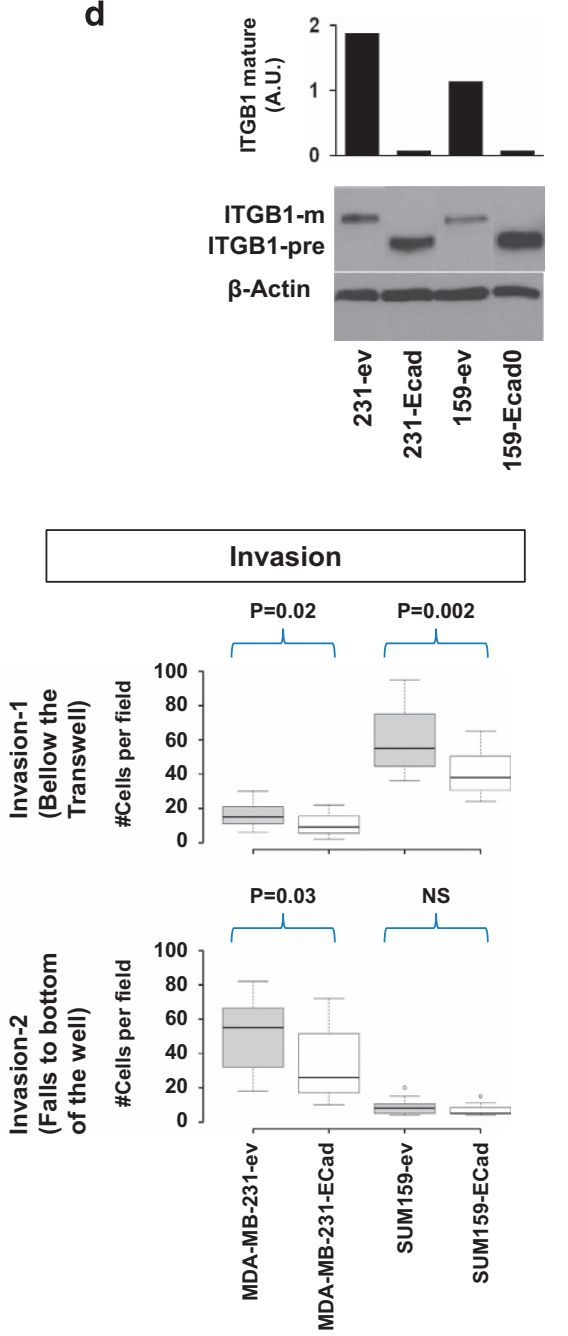

Figure 6. Interaction of MMPs, integrin $\beta 1$, and E-cadherin in metastatic breast cancer cells. (a) MMP-9 and MMP-2 activities in conditioned media from metastatic breast cancer cell lines were analyzed at $48 \mathrm{~h}$ after treatment with the integrin $\beta 1$ binding tetrapeptide RGDS. Secreted MMPs increased with increasing concentrations of RGDS. Values are mean \pm s.d. ${ }^{*} P<0.05$. (b) Cellular integrin $\beta 1$ protein, as analyzed by western blot, did not show any differences when the cells were treated with RGDS. (c) Cellular integrin $\beta 1$ protein levels significantly decreased when metastatic breast cancer cells were treated with the broad-spectrum MMP inhibitor Marimastat or with the MMP-2 and MMP-9 specific inhibitor SC-3BT for $48 \mathrm{~h}$. Values are mean \pm s.d. ${ }^{*} P<0.05$. (d) E-cadherin re-expression in metastatic MDA-MB-231 and SUM159 breast cancer cells resulted in reduced expression of mature integrin $\beta 1$ and elevated expression of the precursor form of integrin $\beta 1$ as compared with empty vector (ev) transfected control cells. (e) E-cadherin re-expressing metastatic cell lines displayed reduced migration and invasion as compared with the corresponding empty vector (ev) control cells. 
inhibition of MMP activities can reduce the expression of active integrin $\beta 1$, suggesting an association between active MMP-2/MMP-9 and integrin $\beta 1$ protein expression in metastatic breast cancer cells. It has previously been shown in human umbilical vein endothelial cells that the physical associations of MMP-2 with integrin $\beta 1$ can promote ECM degradation by these endothelial cells. ${ }^{48}$ In good agreement with these findings, our protein-protein interaction network analysis of human data also predicted an interaction between several MMPs and integrin $\beta 1$.

Metastatic breast cancer remains one of the most devastating cancers, and very few new treatments have revealed meaningful improvements in the survival of advanced stage breast cancer patients. Elevated MMP expression and activity within the degradome is characteristic of metastatic breast tumors and is associated with the development of distant metastases. Even though preclinical studies examining the effectiveness of MMP inhibition were encouraging, clinical studies turned out to be disappointing. We showed for the first time that inhibition of MMPs reduced the cell-ECM adhesion molecule integrin $\beta 1$ expression. We also showed that re-expression of the cell-cell adhesion molecule E-cadherin reduced the active form of integrin $\beta 1$ along with cell migration. We suggest that a treatment strategy that targets critical nodes in the adhesion-degradome network might be the most effective for clinical translation. Elevated MMP levels may be used to identify and monitor women at high risk of developing metastatic disease.

A quarter of the collagen residues in the tumor microenvironment are proline residues. ${ }^{11}$ Therefore, collagen degradation releases a significant amount of proline, which is in turn used in cellular metabolism as a source of energy. Proline can be metabolized by proline oxidase to generate reactive oxygen species as signaling molecules for epigenetic reprogramming, which regulates the redox homeostasis of cancer cells. ${ }^{11,49}$ It was recently shown that metabolic flux can cause changes in cancer cell adhesion and metastatic transformation. ${ }^{50}$ Future studies should focus on the relationship of the metabolome with the adhesome-degradome network in terms of driving breast cancer metastases.

In summary, our study shows for the first time that cancer cell adhesome and degradome interact in metastatic breast cancer cells, and are modulated during migration and invasion of these cancer cells. These results suggest that targeting nodes in the adhesome-degradome network of breast cancer may be an effective strategy for treating metastatic breast cancer.

\section{ACKNOWLEDGMENTS}

This work was supported by NIH R01 CA154725.

\section{CONTRIBUTIONS}

$\mathrm{AR}$ and KG contributed in conception/design, development of methodology, analysis and interpretation of the data, and study supervision. $A R$ and $M C$ contributed in acquisition of the data. AR, ZMB, BK and KG comtributed in writing, review and/or revision of the manuscript. $K G$ provided administrative, technical or material support. $A R, Z M B, B K$ and $K G$ contributed in pathological diagnosis, analyzation and interpretation of the immunohistochemical data. AR, BK, MC and KG carried out experiments and analyzed the data.

\section{COMPETING INTERESTS}

The authors declare no conflict of interest.

\section{REFERENCES}

1 Singletary SE, Connolly JL. Breast cancer staging: working with the sixth edition of the AJCC Cancer Staging Manual. CA Cancer J Clin 2006; 56: 37-47.
2 Okegawa T, Pong RC, Li Y, Hsieh JT. The role of cell adhesion molecule in cancer progression and its application in cancer therapy. Acta Biochim Pol 2004; 51 445-457.

3 Birkedal-Hansen H, Moore WG, Bodden MK, Windsor LJ, Birkedal-Hansen B, DeCarlo A et al. Matrix metalloproteinases: a review. Crit Rev Oral Biol Med 1993; 4: 197-250.

4 Nagase H, Visse R, Murphy G. Structure and function of matrix metalloproteinases and TIMPs. Cardiovasc Res 2006; 69: 562-573.

5 Guo W, Giancotti FG. Integrin signalling during tumour progression. Nat Rev Mol Cell Biol 2004; 5: 816-826.

6 Barczyk M, Carracedo S, Gullberg D. Integrins. Cell Tissue Res 2009; 339: 269-280.

7 Desgrosellier JS, Cheresh DA. Integrins in cancer: biological implications and therapeutic opportunities. Nat Rev Cancer 2009; 10: 9-22.

8 Canel M, Serrels A, Frame MC, Brunton VG. E-cadherin-integrin crosstalk in cancer invasion and metastasis. J Cell Sci 2013; 126: 393-401.

9 Deryugina El, Quigley JP. Matrix metalloproteinases and tumor metastasis. Cancer Metastasis Rev 2006; 25: 9-34.

10 Felding-Habermann B, O'Toole TE, Smith JW, Fransvea E, Ruggeri ZM, Ginsberg $\mathrm{MH}$ et al. Integrin activation controls metastasis in human breast cancer. Proc Natl Acad Sci USA 2001; 98: 1853-1858.

11 Phang JM, Liu W, Hancock C. Bridging epigenetics and metabolism: role of nonessential amino acids. Epigenetics 2013; 8: 231-236.

12 Kohrmann A, Kammerer U, Kapp M, Dietl J, Anacker J. Expression of matrix metalloproteinases (MMPs) in primary human breast cancer and breast cancer cell lines: New findings and review of the literature. BMC Cancer 2009; 9: 188.

13 Brooks PC, Stromblad S, Sanders LC, von Schalscha TL, Aimes RT, StetlerStevenson WG et al. Localization of matrix metalloproteinase MMP-2 to the surface of invasive cells by interaction with integrin alpha $v$ beta 3. Cell 1996; 85: 683-693.

14 Woskowicz AM, Weaver SA, Shitomi Y, Ito N, Itoh Y. MT-LOOP-dependent localization of MT1-MMP to the cell adhesion complexes promotes cancer cell invasion. J Biol Chem 2013; 288: 35126-35137.

15 Steffensen B, Hakkinen L, Larjava H. Proteolytic events of wound-healing-coordinated interactions among matrix metalloproteinases (MMPs), integrins, and extracellular matrix molecules. Crit Rev Oral Biol Med 2001; 12: 373-398.

16 Jiao $Y$, Feng $X$, Zhan Y, Wang R, Zheng S, Liu W et al. Matrix metalloproteinase-2 promotes alphavbeta3 integrin-mediated adhesion and migration of human melanoma cells by cleaving fibronectin. PLoS One 2012; 7: e41591.

17 Gonzalo P, Moreno V, Galvez BG, Arroyo AG. MT1-MMP and integrins: Hand-tohand in cell communication. Biofactors 2008; 36: 248-254.

18 Lynch CC, Matrisian LM. Matrix metalloproteinases in tumor-host cell communication. Differentiation 2002; 70: 561-573.

19 Knoblauch A, Will C, Goncharenko G, Ludwig S, Wixler V. The binding of Mss4 to alpha-integrin subunits regulates matrix metalloproteinase activation and fibronectin remodeling. FASEB $J$ 2007; 21: 497-510.

20 Riikonen T, Westermarck J, Koivisto L, Broberg A, Kahari VM, Heino J. Integrin alpha 2 beta 1 is a positive regulator of collagenase (MMP-1) and collagen alpha 1 (I) gene expression. J Biol Chem 1995; 270: 13548-13552.

21 Whittaker M, Floyd CD, Brown P. Gearing AJ. Design and therapeutic application of matrix metalloproteinase inhibitors. (Chem. Rev. 1999, 99, 2735-2776. Published on the web september 8, 1999). Chem Rev 2001; 101: 2205-2206.

22 Vandenbroucke RE, Libert C. Is there new hope for therapeutic matrix metalloproteinase inhibition? Nat Rev Drug Discov 2014; 13: 904-927.

23 Iwasaki M, Nishikawa A, Fujimoto T, Akutagawa N, Manase K, Endo T et al. Antiinvasive effect of MMI-166, a new selective matrix metalloproteinase inhibitor, in cervical carcinoma cell lines. Gynecol Oncol 2002; 85: 103-107.

24 Jacobsen JA, Major Jourden JL, Miller MT, Cohen SM. To bind zinc or not to bind zinc: an examination of innovative approaches to improved metalloproteinase inhibition. Biochim Biophys Acta 2010; 1803: 72-94.

25 Overall $\mathrm{CM}$, Kleifeld $\mathrm{O}$. Towards third generation matrix metalloproteinase inhibitors for cancer therapy. Br J Cancer 2006; 94: 941-946.

26 Van Lint $\mathrm{P}$, Libert $\mathrm{C}$. Chemokine and cytokine processing by matrix metalloproteinases and its effect on leukocyte migration and inflammation. J Leuk Biol 2007; 82: $1375-1381$.

27 Rizwan A, Bulte C, Kalaichelvan A, Cheng M, Krishnamachary B, Bhujwalla ZM et al. Metastatic breast cancer cells in lymph nodes increase nodal collagen density. Sci Rep 2015; 5: 10002.

28 Gyorffy B, Lanczky A, Eklund AC, Denkert C, Budczies J, Li Q et al. An online survival analysis tool to rapidly assess the effect of 22,277 genes on breast cancer prognosis using microarray data of 1,809 patients. Breast Cancer Res Treat 2009; 123: $725-731$.

29 Hollestelle A, Nagel JH, Smid M, Lam S, Elstrodt F, Wasielewski M et al. Distinct gene mutation profiles among luminal-type and basal-type breast cancer cell lines. Breast Cancer Res Treat 2009; 121: 53-64. 
30 Franceschini A, Szklarczyk D, Frankild S, Kuhn M, Simonovic M, Roth A et al. STRING v9.1: protein-protein interaction networks, with increased coverage and integration. Nucleic Acids Res 2012; 41: D808-D815.

31 Serganova I, Rizwan A, Ni X, Thakur SB, Vider J, Russell J et al. Metabolic imaging: a link between lactate dehydrogenase A, lactate, and tumor phenotype. Clin Cancer Res 2011; 17: 6250-6261.

32 Rizwan A, Serganova I, Khanin R, Karabeber H, Ni X, Thakur S et al. Relationships between LDH-A, lactate, and metastases in 4T1 breast tumors. Clin Cancer Res 2013; 19: 5158-5169.

33 Spitzer M, Wildenhain J, Rappsilber J, Tyers M. BoxPlotR: a web tool for generation of box plots. Nat Methods 2014; 11: 121-122.

34 Minn AJ, Gupta GP, Siegel PM, Bos PD, Shu W, Giri DD et al. Genes that mediate breast cancer metastasis to lung. Nature 2005; 436: 518-524.

35 Ottewell PD, Coleman RE, Holen I. From genetic abnormality to metastases: murine models of breast cancer and their use in the development of anticancer therapies. Breast Cancer Res Treat 2006; 96: 101-113.

36 Gyorffy B, Lanczky A, Szallasi Z. Implementing an online tool for genome-wide validation of survival-associated biomarkers in ovarian-cancer using microarray data from 1287 patients. Endocr Relat Cancer 2012; 19: 197-208.

37 Franken NA, Rodermond HM, Stap J, Haveman J, van Bree C. Clonogenic assay of cells in vitro. Nat Protoc 2006; 1: 2315-2319.

38 Zeng ZS, Cohen AM, Guillem JG. Loss of basement membrane type IV collagen is associated with increased expression of metalloproteinases 2 and 9 (MMP-2 and MMP-9) during human colorectal tumorigenesis. Carcinogenesis 1999; 20: 749-755.

39 Cirri P, Chiarugi P. Cancer associated fibroblasts: the dark side of the coin. Am J Cancer Res 2011; 1: 482-497.

40 Deryugina El, Ratnikov B, Monosov E, Postnova TI, DiScipio R, Smith JW et al. MT1-MMP initiates activation of pro-MMP-2 and integrin alphavbeta3 promotes maturation of MMP-2 in breast carcinoma cells. Exp Cell Res 2001; 263: 209-223.

41 Ruoslahti E. RGD and other recognition sequences for integrins. Annu Rev Cell Dev Biol 1996; 12: 697-715.
42 Hirano Y, Okuno M, Hayashi T, Goto K, Nakajima A. Cell-attachment activities of surface immobilized oligopeptides RGD, RGDS, RGDV, RGDT, and YIGSR toward five cell lines. J Biomater Sci Polym Ed 1993; 4: 235-243.

43 Miranda KC, Khromykh T, Christy P, Le TL, Gottardi CJ, Yap AS et al. A dileucine motif targets E-cadherin to the basolateral cell surface in Madin-Darby canine kidney and LLC-PK1 epithelial cells. J Biol Chem 2001; 276: 22565-22572.

44 Yang JY, Zong CS, Xia W, Wei Y, Ali-Seyed M, Li Z et al. MDM2 promotes cell motility and invasiveness by regulating E-cadherin degradation. Mol Cell Biol 2006; 26: 7269-7282.

45 Mosesson Y, Mills GB, Yarden Y. Derailed endocytosis: an emerging feature of cancer. Nat Rev Cancer 2008; 8: 835-850.

46 Giancotti FG, Ruoslahti E. Integrin signaling. Science 1999; 285: 1028-1032.

47 Yao D, Dai C, Peng S. Mechanism of the mesenchymal-epithelial transition and its relationship with metastatic tumor formation. Mol Cancer Res 2011; 9: 1608-1620.

48 Levkau B, Kenagy RD, Karsan A, Weitkamp B, Clowes AW, Ross R et al. Activation of metalloproteinases and their association with integrins: an auxiliary apoptotic pathway in human endothelial cells. Cell Death Differ 2002; 9: 1360-1367.

49 Liu W, Glunde K, Bhujwalla ZM, Raman V, Sharma A, Phang JM. Proline oxidase promotes tumor cell survival in hypoxic tumor microenvironments. Cancer Res 2012; 72: 3677-3686.

50 Almaraz RT, Tian Y, Bhattarcharya R, Tan E, Chen SH, Dallas MR et al. Metabolic flux increases glycoprotein sialylation: implications for cell adhesion and cancer metastasis. Mol Cell Proteomics 2012; 11: M112 017558.

\section{cc) (i)}

This work is licensed under a Creative Commons Attribution 4.0 International License. The images or other third party material in this article are included in the article's Creative Commons license, unless indicated otherwise in the credit line; if the material is not included under the Creative Commons license, users will need to obtain permission from the license holder to reproduce the material. To view a copy of this license, visit http://creativecommons.org/licenses/ by/4.0/

Supplementary Information accompanies the paper on the npj Breast Cancer website (http://www.nature.com/npjbcancer) 